\title{
Interaction between the C Terminus of NMDA Receptor Subunits and Multiple Members of the PSD-95 Family of Membrane-Associated Guanylate Kinases
}

\author{
Martin Niethammer, Eunjoon Kim, and Morgan Sheng \\ The Howard Hughes Medical Institule, Massachusetts General Hospital, Department of Neurobiology, Harvard Medical \\ School, Boston, Massachusetts 02114
}

\begin{abstract}
Selective concentration and anchoring of ionotropic receptors at the synapse is essential for neuronal signaling. Little is known about the molecules that mediate receptor clustering in the CNS. With use of the yeast two-hybrid system to screen a rat brain cDNA library and by in vitro binding assays, we have identified an interaction between NMDA receptor subunits $2 A$ and $2 \mathrm{~B}$ (NR2A and NR2B) and three distinct members of the PSD-95/SAP90 family of membrane-associated putative guanylate kinases. The interaction is mediated by binding of the $C$ terminus of the NMDA receptor subunits to the first two PDZ (also known as GLGF or DHR) domains of PSD-95/SAP90, an abundant synaptic protein associated with the membrane cy-
\end{abstract}

toskeleton. PSD-95 is also known to bind and cluster Shakertype voltage-gated $\mathrm{K}^{+}$channels. Similarities between the $\mathrm{C}$ termini of NR2 subunits and $\mathrm{K}^{+}$channels suggest a common $\mathrm{C}$-terminal binding motif for PDZ domains. These data suggest that PDZ domains can function as modules for protein-protein interactions. Members of the PSD-95 family might serve to anchor NMDA receptors to the submembrane cytoskeleton and aid in the assembly of signal transduction complexes at postsynaptic sites.

Key words: NMDA receptor; PSD-95; $P D Z$ domain; yeast two-hybrid system; guanylate kinase; cytoskeleton; postsynaptic density
Synapses are specialized cell-cell junctions between neurons, and they exhibit dynamic changes in both activity and morphology. Although synaptic transmission has been studied in detail, and the ultrastructural morphology of synapses has been well described, little is known about the molecular organization of synapses, especially in the CNS. Some abundant components of synapses have been purified by biochemical approaches; examples include actin, calcium/calmodulin dependent kinase II, and PSD-95/ SAP90 (Cho et al., 1992; Garner et al., 1993; Kistner et al., 1993). The synaptic functions of these proteins are poorly understood, however, and their interactions with other proteins remain obscure.

Ionotropic neurotransmitter receptors (NTRs) are specifically concentrated at postsynaptic sites, and different classes of postsynaptic NTRs are segregated from each other in a manner that aligns the appropriate NTR with the proper presynaptic terminal. The molecular mechanisms underlying targeted clustering of NTRs remain obscure, but NTRs presumably interact with proteins that mediate aggregation and attachment to the neuronal membrane cytoskeleton at postsynaptic sites.

Currently, few examples of such molecules are known. At the neuromuscular junction, $43 \mathrm{~K} /$ rapsyn and the dystrophin relative utrophin are involved in acetylcholine-receptor clustering and postsynaptic specialization (Froehner, 1993; Tinsley et al., 1994; Gautam et al., 1995). In the spinal cord, glycine receptors are

Received Oct. 25, 1995; revised Dec. 20, 1995; accepted Dec. 27, 1995.

M.S. is an Assistant Investigator of The Howard Hughes Medical Institute. We thank Jai Up Kim and Adam Rothschild for excellent technical support, and we thank Elaine Aidonidis for help with this manuscript.

Correspondence should be addressed to Dr. Morgan Sheng, Massachusetts General Hospital, Wellmann 423, 50 Blossom Street, Boston, MA 02114.

Copyright $\mathbb{C} 1996$ Society for Neuroscience $0270-6474 / 96 / 162157-07 \$ 05.00 / 0$ clustered because of association with gephyrin, which may link receptor subunits to tubulin (Kirsch et al., 1993).

NMDA receptors represent a major subclass of excitatory ionotropic NTRs in the mammalian brain and have been implicated in mechanisms of activity-dependent synaptic plasticity (Bliss and Collingridge, 1993) and visual cortical development (ConstantinePaton et al., 1990), as well as excitotoxicity (Choi and Rothman, 1990). Currently, minimal data are available on proteins associated with these receptors in the brain. In the brain, NMDA receptors probably exist largely as heteromultimers of the NMDA receplor subunil NR1 complexed with members of the NR2 subfamily (Monyer et al., 1992; Ishii et al., 1993; Sheng et al., 1994). The different NR2 subunits (NR2A-D) show distinct but overlapping expression patterns in the brain and during development (Watanabe et al., 1992; Laurie and Seeburg, 1994; Sheng et al., 1994), and they confer distinct electrophysiological and pharmacological features. NR2 subunits are much larger proteins than NR1 and other glutamate receptor subunits, attributable to an extensive C-terminal sequence of unknown function that is currently modeled to be intracellular (Hollmann et al., 1994; Wo and Oswald, 1994; Bennett and Dingledine, 1995). In the NR2 subunits, this region exceeds 400 amino acids, whereas in the other receptor subunits it typically consists of 50-100 amino acids (Wisden and Seeburg, 1993).

In this study, we have used the yeast two-hybrid system to screen for proteins interacting with NMDA receptors. We report here that subunits NR2A and NR2B bind to multiple members of the same PSD-95/SAP90 family of peripheral membrane proteins that bind and cluster Shaker-type $\mathrm{K}^{+}$channels (Kim et al., 1995). This interaction is mediated by the cytoplasmic tails of NR2A and NR2B, which contain a C-terminal binding motif virtually identical to that found in the $\mathrm{K}^{+}$channel subunits. 


\section{MATERIALS AND METHODS}

Yeast two-hybrid system. Yeast two-hybrid screening was performed using the L40 yeast strain harboring the reporter genes HIS3 and $\beta$-galactosidase $(\beta$-gal) under the control of upstream lexA binding sites (Bartel et al., 1993; Hollenberg et al., 1995; Kim et al., 1995). One hundred milliliters of liquid yeast culture $\left(\mathrm{OD}_{600}=0.25\right)$ were transformed with $50 \mu \mathrm{g}$ of both the bait DNA and the cDNA library and $2 \mathrm{mg}$ of salmon sperm carrier DNA by the lithium acetate method with dimethyl sulfoxide ( $10 \%$ final concentration) (Hill et al., 1991; Hollenberg et al., 1995). After transformation, the yeast was grown for $2 \mathrm{hr}$ in complete yeast medium to allow expression of the HIS3 reporter gene before plating on his ${ }^{-} \mathrm{leu}^{-} \mathrm{trp}^{-}$plates in the presence of $2.5 \mathrm{~mm} 3$-aminotriazole. The baits consisted of the C-terminal 116 (residues 1349-1464, termed NR2A1349c) or 122 (residues 1361-1482, termed NR2B1361c) amino acids of rat NR2A and NR2B, respectively, obtaincd by PCR using specific primers and subcloned in frame with the lexA DNA binding domain into vector $\mathrm{pBHA}$. A shorter lexA fusion construct of NR2B (residues 1453-1482, NR2B1453c) containing just the last 30 amino acids of NR2B was also prepared. The baits were used to screen a rat brain cDNA library (Clontech Laboratories, Palo Alto, CA) constructed in a GAL4 activation domain containing vector pGAD10. DNA of positive interacting clones as assayed by $\beta$-gal staining was isolated from yeast colonies and transformed into MH4 bacteria by electroporation, isolated from the bacteria, and sequenced.

Domain analysis of the interaction. For the domain analysis, different regions of PSD-95/SAP90 were amplified by PCR using specific primers and were fused in frame with the GAL4 activation domain in the EcoRI site of the pGAD10 vector. These constructs were assayed for interaction with the lexA-NR2 constructs by cotransformation into L40 ycast and assay of the two reporter genes, $\beta$-gal and HIS3. $\beta$-Gal activity was quantitated after $2 \mathrm{~d}$ growth on leu $\operatorname{trp}^{-}$plates as the time taken for colonies to turn blue in X-gal filter assays (Bartel et al., 1993) at room temperature. HIS3 activity was measured as percentage growth on his ${ }^{-}$leu ${ }^{-1}$ trp plates in the presence of $2.5 \mathrm{~mm}$ 3-amino-triazole. We found excellent quantitative correlation between HIS3 and $\beta$-gal activity as measured above, as well as with $\beta$-gal measured by a liquid culture $o$-nitrophenyl- $\beta$-galactosidase (ONPG) chromagenic assay (Bartel et al., 1993) (data not shown). We found that the X-gal filter assay and His prototrophy (quantitated as above) were much more sensitive than the ONPG assay, in which weak two-hybrid interactions were impossible to distinguish from background.

Fusion proteins and in vitro binding. Filter overlay assays were performed as in $\mathrm{Li}$ et al. (1992). The C-terminal tails of NR1 (residues 832-938; original splice variant cloned by Moriyoshi et al., 1991), NR2A (residues 1349-1464), NR2B (residues 1361-1482), NR2B (residues 1453-1482), Kv4.2 (residues 409-548), and Kv1.4 (residues 568-655) were subcloned into glutathione- $S$-transferase (GST)-fusion vector pGEX-4T-1 (Pharmacia, Uppsala, Sweden). GST-fusion proteins were prepared as crude bacterial lysates, separated by SDS-PAGE, transferred to nitrocellulose, and incubated with $0.5 \mu \mathrm{g} / \mathrm{ml} \mathrm{H}_{6}$-PSD-95 [hexahistidinetagged fusion protein of PSD-95 (Kim et al., 1995)]. This fusion protein contains amino acid residues 41-355 of PSD-95 and includes the first two PDZ domains. It was purified by Ni-NTA resin column chromatography. Bound $\mathrm{H}_{6}$-PSD-95 was detected by mouse monoclonal anti-T7.Tag antibodies (Novagen, Madison, WI) directed against an epitope tag in the hexahistidine leader sequence. The blots were then stripped and reprobed with $0.5 \mu \mathrm{g} / \mathrm{ml}$ anti-GST antibodies (Santa Cruz Biotcchnology, Santa Cruz, CA) to show the position and relative abundance of the GST-fusion proteins in each lane. HRP-conjugated secondary antibodies and enhanced chemiluminescence (Amersham, Arlington Heights, IL) were used to visualize the bands.

\section{RESULTS}

\section{Two-hybrid screen with NR2A and NR2B C-terminal tail}

The full-length C-terminal tails of NR2A and NR2B starting from the end of putative transmembrane domain IV (residues 836 and 837, respectively) (Ishii et al., 1993) proved to be not useful "baits" for two-hybrid screening because of significant activation of the reporter genes by these fusion constructs alone. Because of especially high sequence conservation at the $\mathrm{C}$ terminus between all members of the NR2 subfamily (see Fig. $5 A$ ), we chose to use

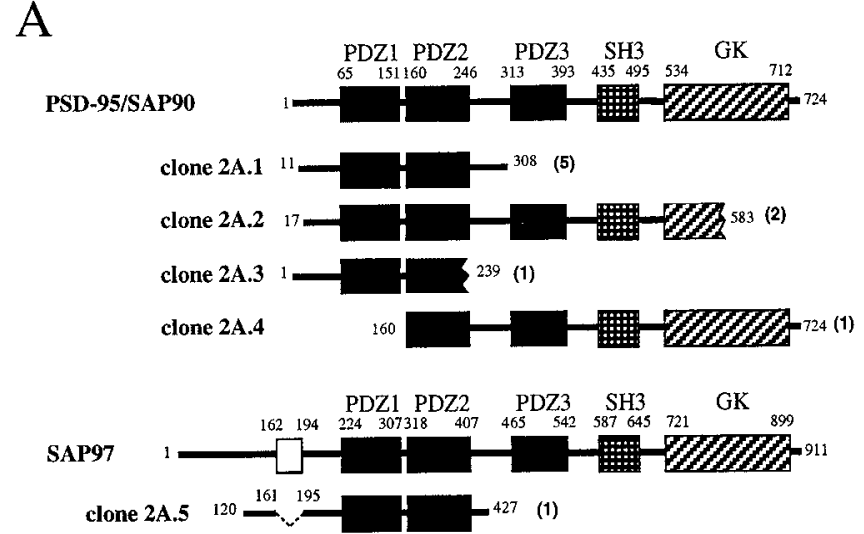

B

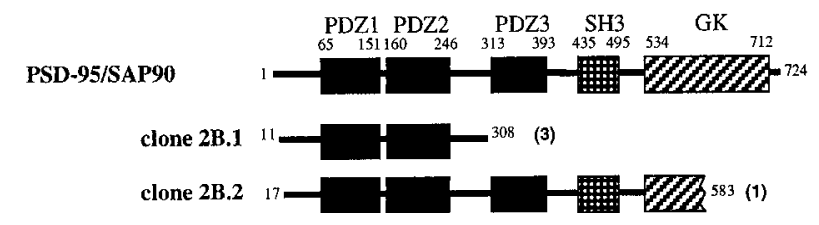

Figure 1. Results of yeast two-hybrid screen with NR2A and NR2B $\mathrm{C}$-terminal baits. The NR2-interacting clones are aligned as fragments of known proteins. $A$, Clones isolated from a screen with NR2A1349c. All clones are fragments of either PSD-95/SAP90 or SAP97. $B$, Clones isolated from a screen with NR2B1361c. Clones 2B.1 and 2B.2 are fragments of PSD-95/SAP90 and are identical to clones 2A.1 and 2A.2 of the screen with NR2A. A schematic representation of the full PSD-95 and SAP97 proteins is shown above the clones, with the PDZ (black), SH3 (stippled), and putative guanylate kinase domains (hatched) (Cho et al., 1992; Müller et al., 1995) shown as boxes. The white box in SAP97 represents an alternative splice variant (Müller et al., 1995). Small numbers refer to amino acid residues, and bold numbers in parentheses indicate the number of times each clone was isolated.

as baits only the C-terminal 116 (NR2A1349c) or 122 (NR2B1361c) amino acids of NR2A and NR2B, respectively.

Approximately 500,000 clones of a rat brain cDNA library were screened with NR2A1349c as bait, yielding five distinct positiveinteracting $\mathrm{CDNAs}$, some of which were isolated multiple times (Fig. $1 A$ ). Clones 2A.1, 2A.2, 2A.3, and 2A.4 are distinct overlapping cDNA fragments of PSD-95/SAP90, an abundant membraneassociated synaptic protein of previously unknown function (Cho et al., 1992; Kistner et al., 1993). Clone 2A.5 was a cDNA fragment of SAP97 (Müller et al., 1995), a relative of PSD-95 with similar sequence and organization (Fig. 1 $A$ ). Both PSD-95 and SAP97 are homologous to the Drosophila tumor suppressor gene lethal (1) disks-large (dlg) (Woods and Bryant, 1989). The strength of binding to these clones with NR2A as assayed by activity of $\beta$-gal and HIS3 reporter genes was similar for all isolated clones of PSD-95/SAP90 and SAP97. These two-hybrid interactions are specific; none of the PSD-95 or SAP97 clones interact with the C-terminal tails of NR1 (splice variant cloned by Moriyoshi et al., 1991) or the voltage-gated $\mathrm{K}^{+}$channel subunit Kv4.2.

Using NR2B1361c as bait, $\sim 1,000,000$ clones of the same library were screened, yielding two distinct strongly interacting clones (Fig. 1B). These two clones, 2B.1 and 2B.2, were fragments of PSD-95 and were identical to clones 2A.1 and 2A.2 from the NR2A screen. Clone 2B.1 was isolated three times. Alignment of the PSD-95 and SAP97 fragments isolated in both screens reveals an overlap in the $\mathrm{N}$-terminal region of these proteins, which contains three PDZ domains, also known as GLGF or DHR 

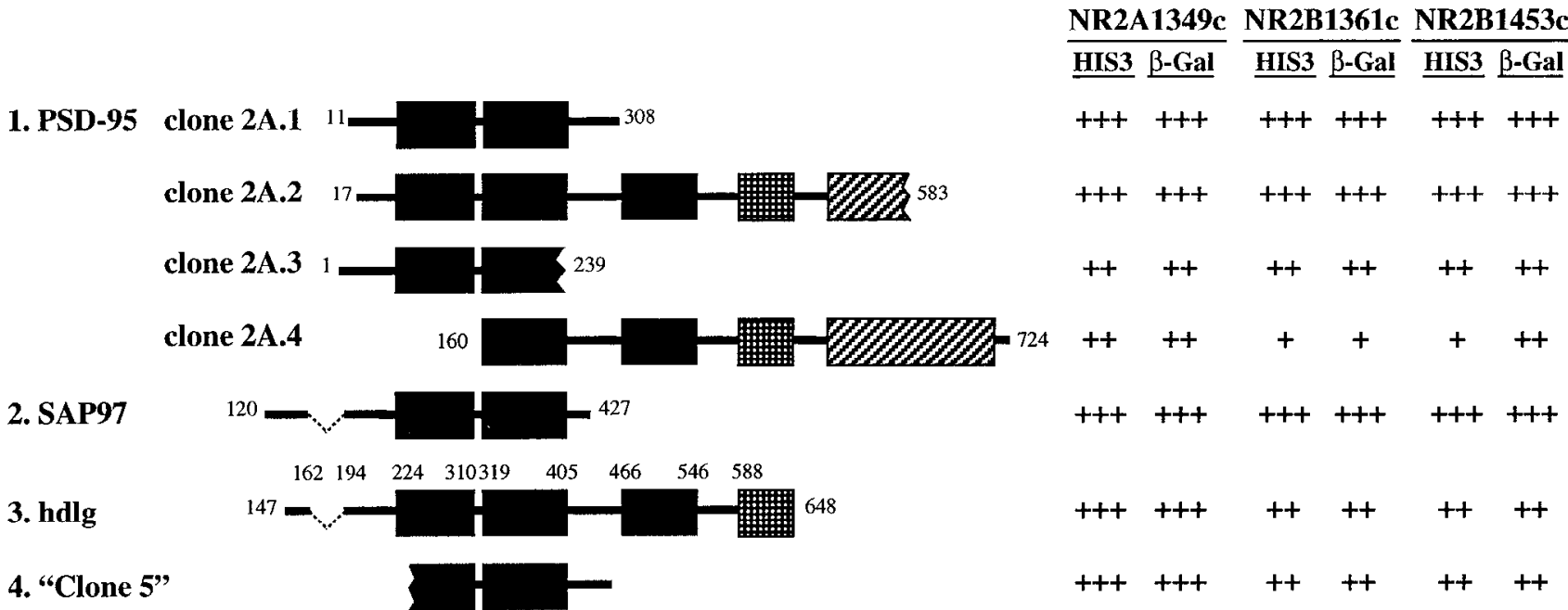

2. SAP97

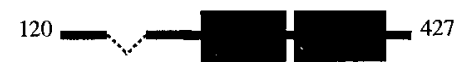

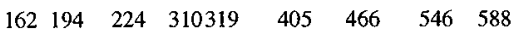

3. hdlg

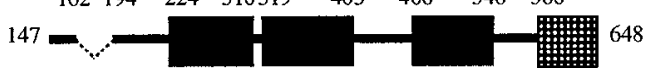

4. "Clone 5"

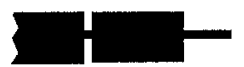

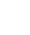

Figure 2. Interaction of NR2A and NR2B with multiple members of the PSD-95 family. Clones 2A.1-2A.4 are the same as in Figure $1 A$. The hdlg clone

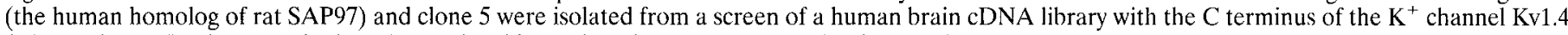
(Kim et al., 1995). The PDZ, SH3, and guanylate kinase domains are represented as boxes as in Figure 1. Strength of interaction was tested for NR2A1349c (NR2A C-terminal residues 1349-1464), NR2B1361c (NR2B C-terminal residues 1361-1482), and NR2B1453c (NR2B C-terminal residues 1453-1482) in the yeast two-hybrid system and measured as the degree of activation of the two reporter genes, HIS 3 and $\beta$-gal. HIS 3 activity (measured by percentage growth of colonies on histidine-lacking medium): $+++(>60 \%),++(30-60 \%),+(10-30 \%),-($ no significant growth); $\beta$-Gal (time taken for colonies to turn blue in X-gal filter lift assays (Bartel et al., 1993): $+++(<25 \mathrm{~min}),++(25-50 \mathrm{~min}),+(50-100 \mathrm{~min}),-($ no significant $\beta$-gal activity).

domains (Cho et al., 1992; Kistner et al., 1993; Müller et al., 1995). These domains have been described in many membraneassociated proteins (including PSD-95, Discs-large, and the tight junction protein ZO-1). Remarkably, all the PSD-95 clones and the SAP97 clone contain the second PDZ repeat (PDZ2) in its entirety, with the exception of clone $2 \mathrm{~A} .3$, which is lacking what is thought to be the last seven amino acids of that domain (Cho et al., 1992; Müller el al., 1995).

\section{Interactions of NR2A and NR2B with multiple members of the PSD-95 family}

We attribute the fact that the NR2B screen isolated only the two most common PSD-95 cDNA fragments from the NR2A screen to a lower screening efficiency of the former screen (Fig. 1). In keeping with this, NR2B1361c was able to interact with all the PSD-95 and SAP97 clones isolated by the NR2A bait with approximately equal affinities, as measured by the yeast two-hybrid system (Fig. 2). A shorter C-terminal bait (NR2B1453c) containing just the last 30 amino acids of NR2B behaved nearly identically to NR2B1361c, indicating that the site of interaction is contained within the C-terminal 30 amino acids (Fig. 2).

Recently, it was demonstrated that the Shaker-type $\mathrm{K}^{+}$channel subunits can bind not only to PSD-95 but also to hdlg, the human homolog of SAP97 (Lue et al., 1994) and a novel, related gene termed "clone 5" (Kim et al., 1995). These $\mathrm{K}^{+}$channel interacting clones were isolated from a human brain cDNA library using the $\mathrm{C}$ terminus of the $\mathrm{K}^{+}$channel subunit Kv1.4 as bait (Kim et al., 1995). To test whether NR2 subunits and Shaker-type subunits display differential specificity in their interaction with PSD-95 and its relatives, the human cDNAs isolated from the Kv1.4 screen were also tested for interaction with the NR2A and NR2B bait constructs. Figure 2 shows that NR2A1349c, NR2B1361c, and NR2B1453c were able to bind efficiently not only PSD-95 but also hdlg and clone 5 . To date we have detected no difference in the specificity of binding between NR2 and Shaker-type subunits to the three different members of the PSD-95 family (PSD-95/ SAP90, hdlg/SAP97, and clone 5). Binding affinity was similar for
NR2B1361c and NR2B1453c, indicating that the C-tcrminal 30 amino acids are sufficient for interaction.

For both NR2A and NR2B, the interaction seemed to be weaker, as judged by reporter gene activity with clone $2 \mathrm{~A} .3$, which lacks the seven C-terminal amino acids of PDZ2 of PSD-95, and with clone 2A.4, which lacks the entire PDZ1, than with clones 2A.1 and 2A.2, which contain both PDZ1 and PDZ2.

\section{Specific interactions of NR2A and NR2B with the first two PDZ repeats of PSD-95}

Strikingly, all cDNAs of PSD-95 family members isolated by the NR2A and NR2B two-hybrid screens contain the second PDZ domain (PDZ2). To investigate further the role of the different domains, we made constructs of these repeats individually (PDZ1, PDZ2, PDZ3) and in combination (PDZ1-2 and PDZ1-2-3) and assayed their interaction with NR2A and NR2B in the yeast two-hybrid system. Both NR2B constructs (NR2B1361c and NR2B1453c) bound much more efficiently to PDZ2 than to PDZ1, as quantitated by the two-hybrid system (Fig. 3). NR2A, however, showed interaction almost as strong with PDZ1 as with PDZ2. Neither NR2A nor NR2B showed detectable binding to PDZ3. This is consistent with the close amino acid sequence identity between PDZ1 and PDZ2 and their relative divergence from PDZ3 at the sequence level (Fig. 5B). Deletion of nine amino acids from the $\mathrm{N}$ terminus of PDZ2 (PDZ2 $\triangle 160-168$ ) abolished interaction with both NR2A and NR2B.

The combination of PDZ1 and PDZ2 (PDZ1-2) did not seem to increase the strength of interaction with NR2A or NR2B over that of PDZ2 alone. This lack of cooperativity of binding of PDZ1 and PDZ2 to NR2 subunits is in apparent contrast to PDZ1-2 binding to the $\mathrm{K}^{+}$channel subunit $\mathrm{Kv1.4}$, which is much stronger than with either PDZ1 or PDZ2 alone (Kim et al., 1995). This may reflect a higher affinity of NR2 binding to PDZ2 compared with $\mathrm{Kv1.4}$, in conjunction with an upper limitation in the linearity of the two-hybrid assay quantitation. 


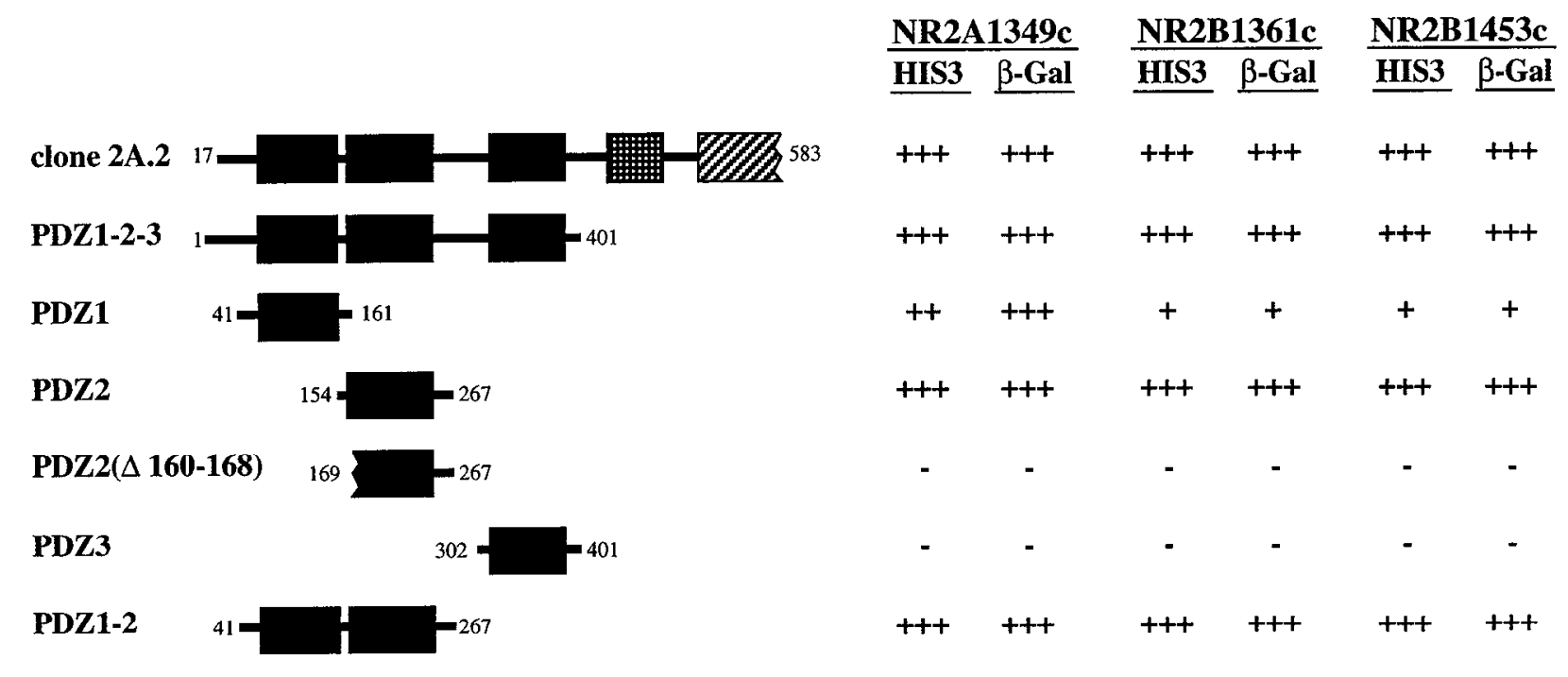

Figure 3. Mapping of the domains of PSD-95, which can bind to NR2A and NR2B. LexA fusion constructs of the different PDZ domains were made and compared with clone $2 \mathrm{~A} .2$ in their interaction with the C termini of NR2A and NR2B. The strength of interaction was measured as activity of reporter genes HIS3 and $\beta$-gdl, quantitated as in Figure 2. PDZ $(\Delta 160-168)$ lacks the N-terminal nine amino acids of PDZ2. The PDZ, SH3, and guanylate kinase domains are represented as boxes as in Figure 1.

\section{In vitro binding of NR2A and NR2B to PSD-95}

To obtain independent confirmation of a direct interaction between NR2 subunits and PSD-95, we performed in vitro binding assays with bacterial fusion proteins. In agreement with previous results (Kim et al., 1995), a hexahistidine-tagged fusion protein of PSD-95 consisting of amino acid residues 41-355 (containing the first two PDZ repeats) bound in the filter overlay assay to the C terminus of the Shaker-type $\mathrm{K}^{+}$channel subunit Kv1.4. PSD-95 also specifically bound to both the NR2Ac and the NR2Bc fusionproteins, including NR2B1453c (Fig. 4, top). No binding was detectable, however, to the GST-protein alone, the Shal-type $\mathrm{K}^{+}$ channel Kv4.2 (Chandy and Gutman, 1995), or the C terminus of NR1 (original splice variant cloned by Moriyoshi et al., 1991). The position and similar abundance of GST-fusion proteins in all lanes was verified by probing the nitrocellulose with an anti-GST antibody (Fig. 4 , bottom). The results of the overlay assay correlate exactly with the yeast two-hybrid assays and confirm a direct binding between PSD-95 and the C termini of NR2A and NR2B.

\section{DISCUSSION}

NR2A and NR2B bind to multiple members of the PSD95 family via their $C$ termini

Using the yeast two-hybrid system and in vitro binding of recombinant proteins, we have identified the brain-specific protein PSD95/SAP90 (Cho et al., 1992; Kistner et al., 1993) as a protein that can bind directly and specifically to the $\mathrm{C}$ terminus of NMDA receptor subunits NR2A and NR2B. During the preparation of the manuscript, Kornau et al. (1995) also identified PSD-95 as a binding partner of NR2 subunits by the yeast two-hybrid system. In addition, we provide evidence that other members of the PSD-95 gene family, such as SAP-97/hdlg (Müller et al., 1995) and a close relative, clone 5 (Kim et al., 1995), can also interact with NR2A and NR2B, and with apparently equal affinity. The interaction is mediated by the $\mathrm{N}$-terminal two $\mathrm{PDZ}$ repeats, $\mathrm{PDZ} 1$ and PDZ2, which are highly conserved (80-90\% identity) in their amino acid sequence between all members of this family and which also bind the $\mathrm{C}$ terminus of the Shaker family of voltagegated $\mathrm{K}^{+}$channels (Kim et al., 1995).
Our results are particularly intriguing because members of the PSD-95 family are close mammalian homologs of the Drosophila tumor suppressor gene dlg (Woods and Bryant, 1989, 1991), which is localized at type I glutamatergic synapses in both pre- and postsynaptic membranes in the Drosophila nervous system (Lahey et al., 1994). Mutations in the dlg gene disrupt synaptic morphology, particularly in the subsynaptic reticulum (I ahey et al., 1994). Those results, taken together with direct binding of NMDA receptor proteins, suggest a role for the PSD-95 family of proteins in the formation and/or maintenance of normal synaptic structure.

\section{C-terminal similarities between NMDA and $\mathrm{K}^{+}$channel subunits define a PDZ domain binding motif}

An important conclusion of this study is that NR2 subunits can bind to the same PSD-95 family proteins as do Shaker-type $\mathrm{K}^{+}$ channel proteins. An alignment of known NR2 subunits with Kv1.4 and the Drosophila ShakerA (ShA) and ShakerB $(\operatorname{ShB})$ channel proteins (Schwarz et al., 1988) shows that these channels share a remarkable similarity in their amino acid sequence at the very C-terminal end (E-S/T-D/E-V) (Fig. 5A). Furthermore, the cytosolic $\mathrm{C}$ terminus of the cell surface receptor Fas, which is capable of direct interaction with a PDZ repeat of the tyrosine phosphatase FAP-1/PTP-BAS (Maekawa et al., 1994; Sato et al., 1995), also shows a related C-terminal sequence (QSLV). Our findings thus support mutational studies of the Kv1.4 C terminus, which indicate that the interaction with PSD-95 is specified by the sequence of the last four amino acids of Shaker-type proteins (Kim et al., 1995). No more than the last 30 amino acids of NR2B are required to interact with PSD-95 in the two-hybrid system (Figs. 2,3) and in an in vitro overlay assay (Fig. 4). On the basis of sequence similarities and recent data from Kornau et al. (1995), it seems reasonable to assume that the interaction in the case of NR2 subunits also involves the C-terminal four amino acids. Mutational studies of Kv1.4 (Kim et al., 1995, and data not shown) indicate that a glutamate or glutamine in the -4 position, a threonine or serine in the -3 position, and a valine in the -1 position are of particular importance for interaction with PSD-95. In particular, a mutational change from the wild-type $\mathrm{Kv} 1.4 \mathrm{C}$ 


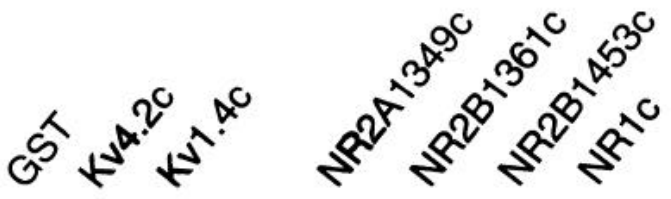

45 -

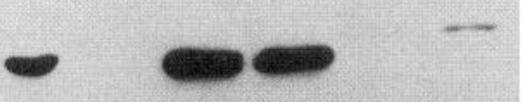

$31=$

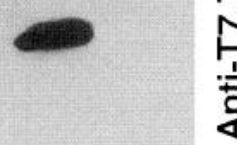

$21.5=$

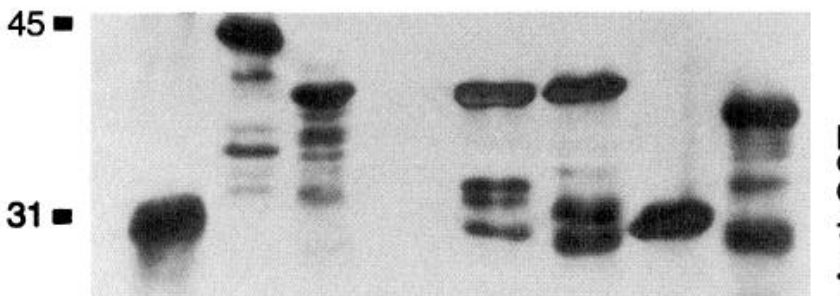

$21.5=$
A

Kv1. 4
ShA
ShB
NR2A
NR2B
NR2C
NR2D
Fas

CSNAKAVETDV NAMAVSIETDV NALAVSIETDV YKKMPSIESDV YEKLSSIESDV WRRVSSLESEV SAHFSSLESEV SNFRNEIQSLV

Figure 4. Filter overlay assay showing in vitro binding of PSD-95 to NR2A and NR2B C-terminal sequences. GST-fusion proteins of various channel subunits were prepared as crude bacterial lysates, separated by SDS-PAGE, and transferred to nitrocellulose. Top, Overlay of the filter with $\mathrm{H}_{6}$-PSD-95 (hexahistidine-labeled fusion protein of PSD-95), demonstrating binding to C-terminal fusion proteins NR2A1349c, NR2B1361c, NR2B1453c, and Kv1.4c but not to NR1c, Kv4.2c, or GST alone. Bottom, The same filter was stripped and reprobed with anti-GST antibody, showing the relative position and abundance of fusion proteins in all lanes. Lower bands in each lane are proteolytic fragments of the GST-fusion proteins. Numbers at left indicate positions of molecular weight markers (in $\mathrm{kDa}$ ).

terminus (ETDV) to ESDV (the C-terminal sequence of NR2A and 2B) preserves Kv1.4 binding to PSD-95 (Kim et al., 1995). Much like Kv1.4, NR2B seems to show a strong preference for PDZ2 over PDZ1 (Fig. 3). In contrast, NR2A seems to show comparable affinity for either PDZ-repeat. This suggests that the amino acids upstream of the C-terminal motif may play a modulatory role in defining the strength and specificity of the interaction.

\section{NMDA receptor interaction with PSD-95 family proteins in vivo}

PSD-95/SAP90 and SAP97 are widely expressed in the brain but show differential subcellular distribution in neurons. PSD-95/ SAP90 was purified as a major component of the postsynaptic density (Cho et al., 1992) but is also present in presynaptic locations (Kistner et al., 1993). SAP97, like PSD-95, seems to be tightly associated with the membrane cytoskeleton but is found predominantly in axons and glutamatergic terminals (Müller et al., 1995). The expression pattern and subcellular distribution of clone 5, a novel third member of the PSD-95 family (Kim et al., 1995), is as yet unknown. NMDA receptors are also ubiquitously expressed in neurons and are predominantly postsynaptic. Recent

Figure 5. A, Similar C-terminal amino acid sequences of different channel and receptor subunits. The Kv1.4 sequence is from Stühmer et al. (1989). The ShA/B are Drosophila Shaker-type $\mathrm{K}^{+}$channels (Schwarz et al., 1988), which also interact with PSD-95 (M. Niethammer, unpublished observations). Fas is a cell-surface receptor capable of interaction with the third PDZ repeat of FAP-1/PTP-BAS (Itoh et al., 1991; Sato et al., 1995). The NR2 sequences are taken from Monyer et al. (1992). A common C-terminal sequence (E-S/T-D/E-V) is found in Shaker-type $\mathrm{K}^{+}$channels and NR2 subunits that bind to PSD-95 family proteins. $B$, Alignment of PDZ domains 1-3 of PSD-95 (Cho et al., 1992; Kistner et al., 1993) and PDZ3 (FAP3) of FAP-1/PTP-BAS (Maekawa et al., 1994), demonstrating similarities unique to PDZ1 and PDZ2 of PSD-95 and FAP3 of FAP-1 but not to PDZ3 of PSD-95, especially in the N-terminal part, which is important for the interaction between NR2 subunits and PDZ2 of PSD-95 (Fig. 3). Identical amino acid residues are boxed in black, and conserved changes are shaded gray. The sequences were aligned using the Wisconsin Sequence Analysis Package program (GCG, Madison, WI).

immunoelectron microscopy studies, however, have consistently shown a fraction of NMDA receptors to be present in axons and glutamatergic terminals (Aoki et al., 1994; Liu et al., 1994). Thus there is extensive overlap in cellular and subcellular distribution of NMDA receptors and PSD-95-type proteins in the nervous system, consistent with the direct association of these proteins in vivo. This is supported further by double immunofluorescence punctate colocalization of NMDA receptors and PSD-95 in cultured hippocampal neurons (Kornau et al., 1995). We have attempted to demonstrate biochemical association of NMDA receptor subunits and PSD-95 by coimmunoprecipitation from brain membranes, but without success. We found PSD-95 to be highly insoluble except in harsh detergents, which seem to disrupt the receptor-PSD-95 complex (E. Kim, unpublished observations). Nevertheless, taken together, the data from yeast two-hybrid, in vitro binding, and immunolocalization experiments suggest that NMDA receptor localization to both postsynaptic and presynaptic sites may be mediated by the direct binding of NR2 subunits to 
PSD-95 and SAP97 and potentially to other members of this family.

Although our studies demonstrate similar affinities of binding of NR2 subunits with PSD-95/SAP90, SAP97/hdlg, and clone 5, it remains to be determined whether NMDA receptors interact differentially in vivo with the various members of this family. This important question is complicated further by the existence of multiple splice variants of SAP97/hdlg (Lue et al., 1994; Müller et al., 1995), each of which could have distinguishable functions.

\section{Implications for synaptic organization and signaling}

In addition to containing three PDZ domains, PSD-95, SAP97, and clone 5 share a common overall protein structure, which includes an SH3 domain and a putative guanylate kinase domain in the C-terminal half of these proteins. $\mathrm{SH} 3$ domains are known to be sites of protein-protein interaction and are found in many signal transduction and cytoskeleton-associated proteins (Pawson, 1995). The proteins that bind to the SH3 domain of PSD-95-like proteins are unknown, but interactions at this site conceivably could allow recruitment of various signaling molecules to the postsynaptic region, directly subjacent to the NMDA receptor channels. This is of special interest because activation of NMDA receptors has been correlated with numerous downstream phosphorylation events, including activation of tyrosine kinases (Bading and Greenberg, 1991).

The function of the guanylate kinase region is unknown, and guanylate kinase activity of this domain has yet to be demonstrated (Koonin et al., 1992; Kistner et al., 1995). The guanylate kinase domain does bind GMP, however (Kistner et al., 1995), suggesting a potential role of PSD-95 in synaptic guanine nucleotide metabolism. Thus, the function of PSD-95 and its relatives may be not only to localize NMDA receptors at synaptic sites but also to form the scaffold of a multiprotein signaling complex immediately beneath the synaptic membrane.

\section{PSD-95 family proteins interact with multiple ion channels}

The N-terminal two PDZ domains of PSD-95 can interact specifically with at least two groups of integral membrane ion channels: Shaker subfamily $\mathrm{K}^{+}$channels and NMDA receptor subunits of the NR2 subfamily. This degeneracy of binding is not surprising because PSD-95 and its relatives represent abundant proteins of the brain, whereas ion channel proteins are relatively rare. Other binding partners of PSD-95 probably remain to be discovered, not only at the PDZ3 site (no ligand yet known) but also additionally at the PDZ1 and PDZ2 domains. PSD-95-like proteins may have a general function of clustering and immobilizing ion channels in neuronal membranes and of nucleating multiprotein signaling complexes in close proximity to them.

\section{Other proteins containing PDZ domains}

We have shown in this study that PDZ domains can function as independent modules for protein-protein interaction. Furthermore, despite the overall sequence similarity, different PDZ domains have distinct binding specificities. For instance, NR2A and NR2B bind to PDZ1 and PDZ2 but not to PDZ3 or the PDZ domain from syntrophin (E. Kim, unpublished observations). In this sense, and because they seem to recognize short-peptide binding motifs, PDZ domains seem to function analogously to the well-known SH2 and SH3 protein-interaction modules (Pawson, 1995).

PDZ domains are found in various proteins in addition to dlg, PSD-95, SAP97, and clone 5. These include the tight- junction proteins ZO-1 (Willott et al., 1993) and ZO-2 (Jesaitis and Goodenough, 1994), the dystrophin-associated protein syntrophin (Adams et al., 1993), and the neuronal isoform of nitric oxide synthase (nNOS) (Nakane et al., 1993), as well as proteins involved in developmental signaling in Drosophila, such as dishevelled (Theisen el al., 1994) and canoe (Miyanoto el al., 1995). In general, these proteins are localized at the inner surface of the cell membrane, particularly at sites of membrane specialization [e.g., ZO-1 at tight junctions and syntrophin and nNOS at the neuromuscular junction (Adams et al., 1993; Willott et al., 1993; Hecker et al., 1994; Kobzik et al., 1994)], but their functions are unknown. The demonstration that a synapse-associated family of PDZ-containing proteins (typified by PSD-95) interacts directly with membrane ion channels suggests that the roles of other PDZ-containing proteins also may be to organize specific protein complexes at functionally specialized sites at the cell surface.

\section{REFERENCES}

Adams ME, Butler MH, Dwyer TM, Peters MF, Murnane AA, Froehner SC (1993) Two forms of mouse syntrophin, a $58 \mathrm{kd}$ dystrophinassociated protcin, differ in primary structurc and tissuc distribution. Neuron 11:531-540.

Aoki C, Venkatesan C, Go C-G, Mong JA, Dawson TM (1994) Cellular and subecllular localization of NMDA-R1 subunit immunoreactivity in the visual cortex of adult and neonatal rats. J Neurosci 14:5202-5222.

Bading H, Greenberg ME (1991) Stimulation of protein tyrosine phosphorylation by NMDA receptor activation. Science 253:912-914.

Bartel PL, Chien C-T, Sternglanz R, Ficlds S (1993) Using the twohybrid system to detect protein-protein interactions. In: Cellular interactions in development: a practical approach (Hartley D, ed), pp 153179. Oxford: Oxford UP.

Bennett JA, Dingledine R (1995) Topology profile for a glutamate receptor: three transmembrane domains and a channel-lining re-entrant membrane loop. Neuron 14:373-384.

Bliss TVP, Collingridge GL (1993) A synaptic model of memory: longterm potentiation in the hippocampus. Nature 361:31-39.

Chandy KG, Gutman GA (1995) Voltage-gated $\mathrm{K}^{+}$channels. In: Ligandand voltage-gated ion channels (North R, ed), pp 1-72. Boca Raton: CRC.

Cho K-O, Hunt CA, Kennedy MB (1992) The rat brain postsynaptic density fraction contains a homolog of the Drosophila discs-large tumor suppressor protein. Neuron 9:929-942.

Choi DW, Rothman SM (1990) The role of glutamate neurotoxicity in hypoxic-ischemic neuronal death. Annu Rev Neurosci 13:171-182.

Constantine-Paton M, Cline HT, Debski E (1990) Patterned activity, synaptic convergence, and the NMDA receptor in developing visual pathways. Annu Rev Neurosci 13:129-154.

Froehner SC (1993) Regulation of ion channel distribution at synapses. Annu Rev Neurosci 16:347-368.

Garner CC, Garner A, Voss B, Appeltauer U, Gundelfinger E (1993) Identifying novel synapse associated proteins. In: Neuronal cytoskeleton-morphogenesis, transport and synaptic transmission (Hirokawa $\mathrm{N}$, ed), pp 317-329. Tokyo: Japanese Scientific Society.

Gautam M, Noakes PG, Mudd J, Nichol M, Chu GC, Sanes JR, Merlie JP (1995) Failure of postsynaptic specialization to develop at neuromuscular junctions of rapsyn-deficient mice. Nature 377:232-236.

Hecker M, Mülsch A, Busse R (1994) Subcellular localization and characterization of neuronal nitric oxide synthase. J Neurochem 62:1524-1529.

Hill J, Donald KAIG, Griffiths DE (1991) DMSO-enhanced whole cell yeast transformation. Nucleic Acids Res 19:5791.

Hollenberg SM, Sternglanz R, Cheng PF, Weintraub H (1995) Identification of a new family of tissue-specific basic helix-loop-helix proteins with a two-hybrid system. Mol Cell Biol 15:3813-3822.

Hollmann M, Maron C, Heinemann S (1994) N-glycosylation site tagging suggests a three transmembrane domain topology for the glutamate receptor GluR1. Neuron 13:1331-1343.

Ishii T, Moriyoshi K, Sugihara H, Sakurada K, Kadotani H, Yokoi M, Akazawa C, Shigemoto R, Mizuno N, Masu M, Nakanishi S (1993) Molecular characterization of the family of the $N$-methyl-D-aspartate receptor subunits. J Biol Chem 268:2836-2843. 
Itoh N, Yonehara S, Ishii A, Yonehara M, Mizushima S, Sameshima M, Hase A, Seto Y, Nagata S (1991) The polypeptide encoded by the cDN $\Lambda$ for human cell surface antigen Fas can mediate apoptosis. Cell 66:233-243.

Jesaitis LA, Goodenough DA (1994) Molecular characterization and tissue distribution of $\mathrm{ZO}-2$, a tight junction protein homologous to $\mathrm{ZO}-1$ and the Drosophila discs-large tumor suppressor protein. J Cell Biol 124:949-961.

Kim E, Niethammer M, Rothschild A, Jan YN, Sheng M (1995) Clustering of Shaker-type $\mathrm{K}^{+}$channels by direct interaction with a family of membrane-associated guanylate kinases. Nature 378:85-88.

Kirsch J, Wolters I, Triller A, Betz H (1993) Gephyrin antisense oligonucleotides prevent glycine receptor clustering in spinal neurons. $\mathrm{Na}$ ture 366:745-748.

Kistner U, Wenzel BM, Veh RW, Cases-Langhoff C, Garner AM, Appeltauer U, Voss B, Gundelfinger ED, Garner CC (1993) SAP90, a rat presynaptic protein related to the product of the Drosophila tumor suppressor gene dlg-A. J Biol Chem 268:4580-4583.

Kistner U, Garner CC, Linial M (1995) Nucleotide binding by the synapse associated protein SAP90. FEBS Lett 359:159-163.

Kobzik L, Reid MB, Bredt DS, Stamler JS (1994) Nitric oxide in skeletal muscle. Nature 372:546-548.

Koonin EV, Woods DF, Bryant PJ (1992) dlg-R proteins: modified guanylate kinases. Nature Genet 2:256-257.

Kornau H-C, Schenker LT, Kennedy MB, Seeburg PH (1995) Domain interaction between NMDA reccptor subunits and the postsynaptic density protein PSD-95. Science 269:1737-1740.

Lahey T, Gorczyca M, Jia X-X, Budnik V (1994) The Drosophila tumor suppressor gene $d l g$ is required for normal synaptic bouton structure. Neuron 13:823-835.

Lauric DJ, Secburg PH (1994) Regional and developmental heterogencity in splicing of the rat brain NMDAR1 mRNA. J Neurosci 14:3180-3194.

Li M, Jan YN, Jan LY (1992) Specification of subunit assembly by the hydrophilic amino-terminal domain of the Shaker potassium channel. Science 257:1225-1230.

Liu H, Wang H, Sheng M, Jan LY, Jan YN, Basbaum AI (1994) Evidence for presynaptic $N$-methyl-D-aspartate autoreceptors in the spinal cord dorsal horn. Proc Natl Acad Sci USA 91:8383-8387.

Lue RA, Marfatia SM, Branton D, Chishti AH (1994) Cloning and characterization of hdlg: the human homologue of the Drosophila discslarge tumor suppressor binds to protein 4.1. Proc Natl Acad Sci USA 91:9818-9822.

Maekawa K, Imagawa N, Nagamatsu M, Harada S (1994) Molecular cloning of a novel protein-tyrosine phosphatase containing a membranebinding domain and GLGF repcats. FEBS Lett 337:200-206.

Miyamoto H, Nihonmatsu I, Kondo S, Ueda R, Togashi S, Hirata K, Ikegami Y, Yamamoto D (1995) Canoe encodes a novel protein containing a GLGF/DHR motif and functions with Notch and scabrous in common developmental pathways in Drosophila. Genes Dev 9:612-625.

Monyer H, Sprengel R, Schoepfer R, Herb A, Higuchi M, Lomeli H, Burnashev N, Sakmann B, Seeburg PH (1992) Heteromeric NMDA receptors: molecular and functional distinction of subtypes. Science 256:1217-1221.

Moriyoshi K, Masu M, Ishii T, Shigemoto R, Mizuno N, Nakanishi S (1991) Molecular cloning and characterization of the rat NMDA receptor. Nature 354:31-37.

Müllcr BM, Kistner U, Veh RW, Cases-Langhoff C, Becker B, Gundelfinger ED, Garner CC (1995) Molecular characterization and spatial distribution of SAP97, a novel presynaptic protein homologous to SAP90 and the Drosophila discs-large tumor suppressor protein. J Neurosci 15:2354-2366.

Nakane M, Schmidt HH, Pollock JS, Forstermann U, Murad F (1993) Cloned human brain nitric oxide synthase is highly expressed in skeletal muscle. FEBS Lett 316:175-180.

Pawson T (1995) Protein modules and signalling networks. Nature 373:573-580.

Sato T, Irie S, Kitada S, Reed JC (1995) FAP-1: a protein tyrosine phosphatase that associates with Fas. Science 268:4I1-415.

Schwarz TL, Tempel BL, Papazian DM, Jan YN, Jan LY (1988) Multiple potassium-channel components are produced by alternative splicing at the Shaker locus in Drosophila. Nature 331:137-145.

Sheng M, Cummings J, Roldan LA, Jan YN, Jan LY (1994) Changing subunit composition of heteromeric NMDA receptors during development of rat cortex. Nature 368:144-147.

Stühmer W, Ruppersberg JP, Schroter KH, Sakmann B, Stocker M, Glese KP, Perschke A, Baumann A, Pongs O (1989) Molccular basis of functional diversity of voltage-gated potassium channels in mammalian brain. EMBO J 8:3235-3244.

Theisen H, Purcell J, Bennett M, Kansagara D, Syed A, Marsh JL (1994) Dishevelled is required during wingless signaling to establish both cell polarity and cell identity. Development 120:347-360.

Tinsley JM, Blake DJ, Zuellig RA, Davies KE (1994) Increasing complexity of the dystrophin-associated protein complex. Proc Natl Acad Sci USA 91:8307-8313.

Watanabe M, Inoue Y, Sakimura K, Mishina M (1992) Developmental changes in distribution of NMDA receptor channel subunit mRNAs. NeuroReport 3:1138-1140.

Willott E, Balda MS, Fanning AS, Jameson B, Van Itallie C, Anderson JM (1993) The tight junction protein ZO-1 is homologous to the Drosophila discs-large tumor suppressor protein of septate junctions. Proc Natl Acad Sci USA 90:7834-7838.

Wisden W, Seeburg PH (1993) Mammalian ionotropic glutamate receptors. Curr Opin Neurobiol 3:291-298.

Wo ZG, Oswald RE (1994) Transmembrane topology of two kainate receptor subunits revealed by N-glycosylation. Proc Natl Acad Sci USA 91:7154-7158.

Woods DF, Bryant PJ (1989) Molecular cloning of the lethal (1) discs large-1 oncogene of Drosophila. Dev Biol 134:222-235.

Woods DF, Bryant PJ (1991) The discs-large tumor suppressor gene of Drosophila encodes a guanylate kinase homolog localized at septate junctions. Cell 66:451-464. 